\title{
Correction to: Burden of caregivers of adult patients with schizophrenia in a predominantly African ancestry population
}

\author{
Gabrielle Alexander ${ }^{1}$. Charlotte-Ellen Bebee ${ }^{1} \cdot$ Kelly-Marie Chen $^{1} \cdot$ Ross-Michael Des Vignes ${ }^{1} \cdot$ Brandon Dixon $^{1}$. \\ Richard Escoffery $^{1}$ - Chazine Francis ${ }^{1}$. DeAngelo Francis ${ }^{1} \cdot$ Zahra Mendoza $^{1} \cdot$ Shenae Miller ${ }^{3}$. Skyla Montano ${ }^{1}$. \\ Maxine Nelson ${ }^{1}$. Stephon Ramcharan ${ }^{1}$ - Siobhan Richards ${ }^{1} \cdot$ Maria D. Jackson $^{2}$
}

Published online: 11 January 2019

(c) Springer Nature Switzerland AG 2019

\section{Correction to: Qual Life Res (2016) 25:393-400 https://doi.org/10.1007/s11136-015-1077-5}

In the original publication, the co-author name Kelly-Marie Chen was misspelled and Shenae Miller was missed in the author group. The correct author group has been provided in this correction.

The original article can be found online at https://doi.org/10.1007/ s11136-015-1077-5.

Maria D. Jackson maria.jackson@uwimona.edu.jm

1 Community Health Rotation, Department of Community Health and Psychiatry, The University of the West Indies, Mona, Jamaica

2 Department of Community Health and Psychiatry, The University of the West Indies, Mona, Kingston 7, Jamaica

3 The University of the West Indies, Mona, Jamaica 